\title{
Intimate Partner Violence: What Are Physicians' Perceptions?
}

\author{
Therese Zink, MD, MPH, Saundra Regan, MGS, Linda Goldenhar, PhD, \\ Stephanie Pabst, MEd, and Barb Rinto, MPA
}

Background: Intimate partner violence (IPV) is common in primary care; $11 \%$ to $22 \%$ of women experienced physical abuse in the past year. Older women experience IPV as well, but it is often undetected. This study examined primary care providers' awareness about IPV in older women, including their screening practices and management.

Methods: Interviews and focus groups were conducted with 44 primary care providers. Thematic analysis was used to identify common themes.

Results: Providers fell along a continuum of thoroughness for identifying and managing IPV in older women, ranging from suboptimal to thorough identification of IPV and suboptimal to thorough management of the patient. In addition to the barriers commonly reported about IPV screening in younger women, providers described limited understanding of the diagnoses commonly associated with IPV, frustration with older women's unwillingness to disclose problems and ask for help, and limited community services that accommodate older women with IPV. Providers recommended that communities sponsor public awareness campaigns about IPV as a problem for all women and that aging and IPV agencies work together.

Conclusions: Continued provider training about IPV should include information on identifying older victims and appropriate management options. Participants stressed the importance of community efforts to raise awareness and improve resources available for older women who are victims of IPV. (J Am Board Fam Pract 2004;17:332-40.)

Intimate partner violence (IPV), psychological/ emotional abuse, controlling behaviors, threats, physical and sexual abuse between adults in the home,${ }^{1}$ is frequently encountered in the primary care setting. Studies demonstrate physical abuse rates of $11 \%$ to $22 \%$ in the past year among adult female patients. ${ }^{2-4}$ Prevalence and incidence of physical abuse in women over 55 years of age in primary care practices are $4 \%$ and $1 \%$, respectively (Zink T, Fisher B, Pabst S, Regan S. The preva-

Submitted, revised, 9 March 2004.

From the Department of Family Medicine (TZ, SR, SP), Institute of Health Policy and Health Services Research (LG), and the Women's Center (BR), University of Cincinnati, Cincinnati, OH. Address correspondence to Therese Zink, MD, MPH, Dept. of Research, Olmsted Medical Center, 210 9th Street SE, Rochester, MN 55904 (e-mail: tzink@olmmed.org).

This work was supported under award R605H23525 from the Attorney General of Ohio, Betty Montgomery. The points of view in this article are those of the authors and do not necessarily represent the official position of the office of the Attorney General of Ohio.

This work was presented previously as a poster at the Ohio Academy of Family Practice Research Day; 2003 Apr 12; Columbus, OH; and at the Family Violence Prevention Fund meeting; 2002 Sept 27-28; Atlanta, GA. lence and incidence of domestic violence in older women in primary care practices. Submitted for publication). One might assume that because of the physical and mental health consequences of IPV, older women with IPV commonly visit their physicians.

Although professional organizations ${ }^{8-10}$ encourage screening of women, physicians are doing an inadequate job of screening women of all ages for IPV. Ten percent or less of adult providers routinely screen their patients for IPV. ${ }^{11-14}$ Barriers to screening include time constraints, discomfort with the subject, fear of offending the patient, frustration with patient's denial, lack of skills and resources to manage IPV, and the fear of opening "Pandora's box."15-18 For these reasons, and because physicians do not think of older women as victims of IPV, screening for IPV rarely occurs with older patients. ${ }^{19}$

In addition, the generational challenges of caring for older women with IPV-family issues are personal business and marriage is a lifetime commitment even if there is abuse, ${ }^{20}$ - and the limited community resources available for these wom- 
en ${ }^{21,22}$ make identifying and managing these older patients even more difficult. To date, studies have not examined this issue. The purpose of this study was to understand primary care providers' awareness of IPV in women over 55 years of age.

\section{Methods}

A convenience sample of primary care provider practices in southwestern Ohio were identified because one of their physicians was a graduate from the University of Cincinnati medical school or involved with a local professional organization (American Academy of Family Practice, American Women's Medical Association, and Academy of Medicine). Practices were contacted and asked to participate in a focus group about the issue of IPV and older women. Twenty practices -7 urban, 11 suburban, and 2 small town-with 44 primary care providers agreed to participate. Focus groups (13) and interviews (3) were held between March and August 2002. One focus group included providers from 5 different practices who were involved in the same professional organization. A single session was held that lasted about 1 hour, either over lunch or at the end of the day. Focus group attendance ranged from 2 to 5 participants. Participants came and went from the session as their schedules allowed. We included the input of nurse managers at 2 sites because they seemed to know many of the patients and were the decision-makers about clinic resources. Because of physician availability, 3 of the sessions were conducted solely as one-on-one interviews. Participant demographics are presented in Table 1.

The facilitator, a primary care physician, followed the interview grid shown in Table 2. One or more research assistants were present at each session and took detailed notes. Immediately after the session, notes were compiled, typed, and entered into Ethnograph, a software program for qualitative analysis. ${ }^{23}$ Three qualitative researchers (physician, gerontologist, and behavioral scientist) read each transcript to identify overarching themes. These themes were further divided into more targeted categories. Disagreements were resolved by discussion until consensus was reached. ${ }^{24}$ Because of the variability of individual providers' knowledge and management of IPV in women over 55, we used the provider as the unit of analysis instead of the practice. A model depicting the themes was
Table 1. Demographics of Respondents Participating in Focus Groups and Interviews

\begin{tabular}{lcr}
\hline Type of Practitioner $(\mathrm{n}=44)$ & $\mathrm{n}$ & $\%$ \\
\hline Family Medicine Physician & 29 & 65.9 \\
$\quad$ Physician Extenders & 2 & 4.5 \\
Internal Medicine Physician & 9 & 20.5 \\
Gynecologist & 2 & 4.5 \\
Nurse Manager & 2 & 4.5 \\
Race & & \\
White & 38 & 86.4 \\
African American & 5 & 11.4 \\
$\quad$ Asian & 1 & 2.2 \\
Gender & 28 & \\
$\quad$ Male & 16 & 63.6 \\
Female & Mean & 36.4 \\
& 46.0 & SD \\
\hline Age (years) & 15.6 & 9.0 \\
Years in Practice & & 9.9 \\
\hline
\end{tabular}

developed and refined over several meetings. In an effort to establish some level of the model's validity, 10 providers who had not participated in the sessions and were knowledgeable about IPV reviewed and provided feedback about the model. Minor changes were made to improve the model's clarity.

\section{Results}

Three primary themes were discovered from the data: (1) providers' methods and procedures used (or not used) to identify and manage; (2) barriers to identifying and managing; and, finally, (3) strategies suggested to enhance awareness and services.

\section{Table 2. Interview Questions and Probes}

1. Do you screen for intimate partner violence (IPV)?

If yes, 'Have you seen older women who are victims of intimate partner violence in your practice?'

If no, 'Do you have older female patients with chronic physical/somatic complaints?'

Tell me about those patients.

Do you have female patients with chronic mental issues such as depression or anxiety?

Tell me about those patients.

2. How do you manage those patients?

3. Do you know who your local domestic violence crisis agency is?

What has been your experience with these agency/ agencies?

4. What is you experience with Adult Protective Services?

What about other agencies for seniors?

5. What do you need to do a better job with IPV? 


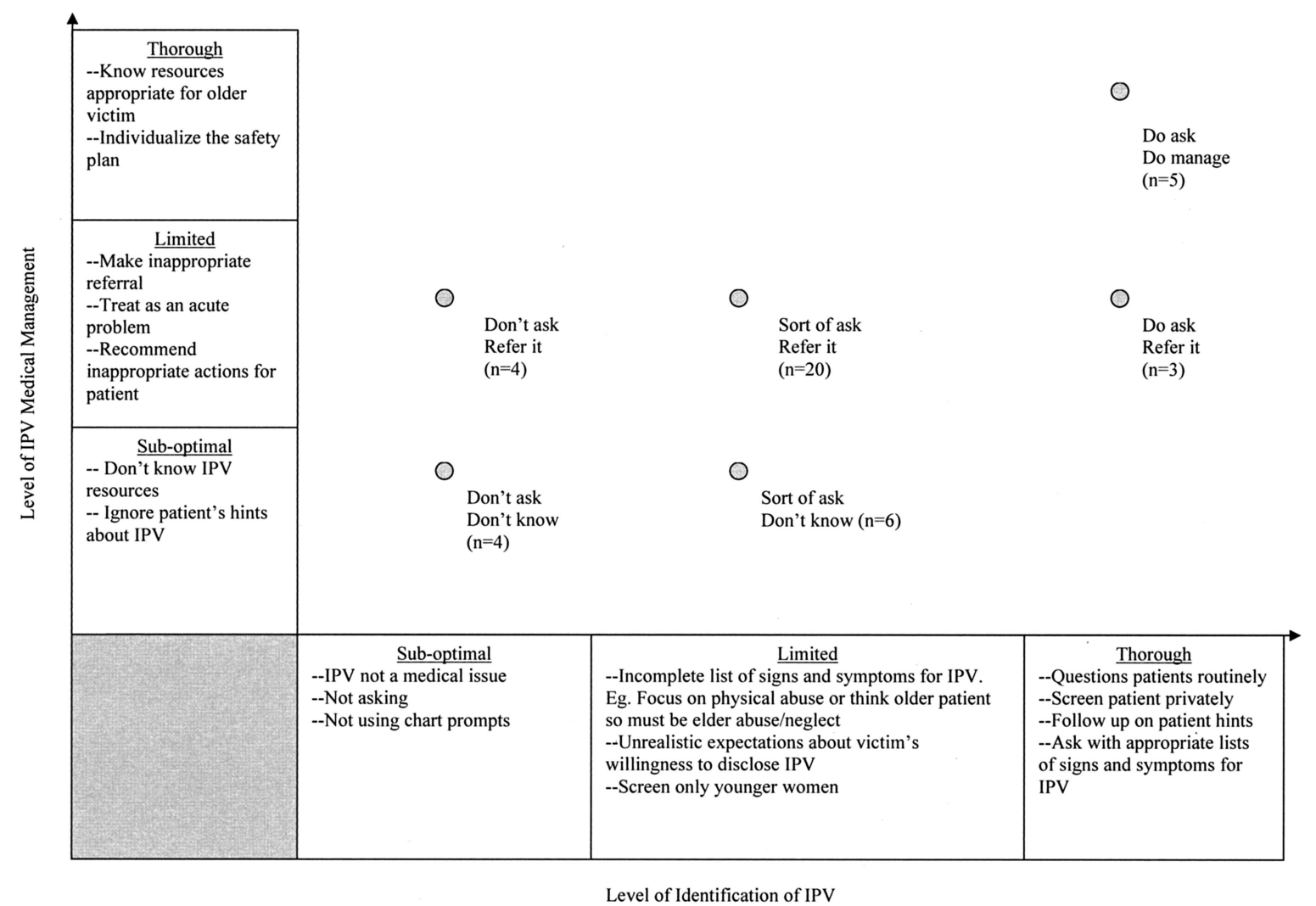

Figure 1. Variation in providers' level of identification and management of older patients with IPV. The horizontal axis/continuum corresponds to the degree to which providers actively attempted to identify IPV among their older female patients (ie, suboptimal identification, limited identification, and thorough identification). The vertical axis/continuum corresponds to the extent to which providers manage the patients who have been diagnosed as victims of IPV (ie, suboptimal, limited, and thorough management). The intersection of suboptimal or limited identification and thorough management and thorough identification and suboptimal management are unlikely and were not found among our participants, so these intersections are not explored. ( $n=42$; office/nurse managers were not assigned a position in the model because they did not see patients.)

\section{Providers' Methods and Procedures}

There are 2 aspects to this overarching theme: (1) what a provider does to identify whether or not an older woman patient is a victim of IPV and (2) how a provider manages the patient if IPV is diagnosed or suspected. To visually depict these 2 aspects and the interactions between them, we developed a 2-dimensional model (Figure 1). Our findings indicate that providers typically fall somewhere along the 2 continuums of (1) identifying IPV and (2) managing IPV, depending on their attitudes, knowledge, and/or behaviors regarding IPV among their older women patients. The ranges of behavior along the continuums go from "suboptimal" to "thorough" with classifications labeled suboptimal, limited, and thorough. The interactions of these classifications along the 2 continuums create 6 catego- ries. The 6 categories were titled to represent the types of IPV identification and management activities of the practitioner. These titles will be referred to when the categories are described. First, the 2 corners of the model, the intersections of suboptimal identification and suboptimal management and the intersections of thorough identification and thorough management, will be described. The number of providers that fell into each of these anchor categories for older women with IPV is noted. Male and female providers were distributed throughout the continuums.

\section{Don't Ask; Don't Know}

Suboptimal identification and suboptimal management (4 providers) includes those providers that 
clearly stated that they were not screening for IPV in any patients:

We are not looking for new problems to screen for. We can't even screen for all the major problems.... I don't know how to fix this problem [IPV].

I have a 20-year established practice. I don't have patients like that.

This was particularly true of providers who had a predominantly suburban or rural practice. Another, somewhat curious, example of suboptimalidentifying and suboptimal-managing behaviors was the provider who said, "We have IPV stickers in our charts, but I don't use them." Providers in this category did not believe that IPV was a medical issue, did not think that there were medical solutions, and did not know where to refer or how to manage an IPV victim, no matter what her age.

\section{Do Ask; Do Manage}

At the other end of the continuums is this category-thorough identification and thorough management (5 providers). Focus group participants described certain behaviors that could be used to categorize a provider into this category:

She [the patient] is on an SSRI and Lorazepam.... I referred her to a clinical psychologist and she was getting support from ber church. There were a lot of ups and downs. Her husband did threaten to kill her once.

He used to hit her. . now there is emotional abuse going on. She is a somatisizer [sic] with a long list of problems. She depends on him for driving. She won't leave the relationship. I manage her with frequent visits.

The IPV agency wants victims to leave. That does not always work for older victims.

These providers displayed a "chronic disease" mindset for managing IPV, ongoing attention to a variety of factors, and understanding of the unique challenges of managing the older victim who often needs to seek solutions other than leaving the relationship and the varied capacities of local resources to meet the needs of the older IPV victim.

Next, the 4 middle categories of the continuums are examined.

\section{Sort of Ask, Don't Know}

This category includes limited identification and suboptimal management (6 providers). Providers were classified here if they conducted behaviors that provided only a limited level of identifying IPV among older women and they inadequately managed the situation. This category includes providers who "screen only women under 40 " or "only when the patient brings up the issue of abuse do we talk about it." One office screened, but not in a private area away from the spouse:

We screen as part of the intake assessment. . in a room with cubicles and several people; it is not the most private area.

Some providers had an incomplete understanding of the "red flag" symptoms and diagnoses, presenting ailments that are associated with IPV or that might lead providers to be "suspicious of IPV." Examples include: only considering physical abuse as symptomatic for IPV and thinking of the signs of elder abuse and neglect because it was an older patient:

I screen occasionally if there is an injury or complaints. . . injuries that don't make sense.

I ask if I suspect abuse like bruises or with the elderly, dementia, forgetful, unkempt, dressed inappropriately....

When probed, these providers were seeing patients with chronic somatic complaints and mental health diagnoses, conditions that are frequently associated with IPV, but had not thought of screening these patients for IPV. ${ }^{7}$ Discussion of these cases during the focus groups caused some of the providers to acknowledge that they should screen some of their older patients for IPV.

\section{Don't Ask; Refer It}

This category includes suboptimal identification and limited management (4 providers). These providers reported that they "called the police" or "called Adult Protective Services" to deal with an obvious case of IPV without further probing the situation. They knew something needed to be done but were unfamiliar with the range and nuances of resources for older women with IPV.

\section{Sort of Ask; Refer It}

This category includes limited identification and limited management (20 providers). These providers seemed to work primarily with an "acute disease" model-identify and treat the problem and then move on to the next issue. Examples included: treating depression or anxiety, but not exploring the IPV or providing such unrealistic advice as, "I told her to leave." 


\begin{tabular}{|c|c|}
\hline Barriers & Illustrative Quotes from the Focus Groups \\
\hline \multicolumn{2}{|l|}{ Victims } \\
\hline Accept as inevitable & $\begin{array}{l}\text { 'Older women are more likely to expect their husbands to yell and abuse them, but } \\
\text { you stay married because that is what you do and then you celebrate that } 50 \text { th } \\
\text { wedding anniversary.' }\end{array}$ \\
\hline Reluctant to seek help & $\begin{array}{l}\text { 'She is } 72 \text {, says her husband is an SOB, he's chased away all her friends, but she won't } \\
\text { do anything ... it is generational. I suggested counseling, she's not interested.' }\end{array}$ \\
\hline Intertwined lives, lots to lose & $\begin{array}{l}\text { 'The more privilege, the harder to confront what is not working in the marriage. } \\
\text { They are wedded to the husband and what he brings to the marriage.' }\end{array}$ \\
\hline \multicolumn{2}{|l|}{ Providers } \\
\hline Attitude barriers & 'It does not have medical solutions and so it's not my job to try to find it.' \\
\hline Lack of knowledge about IPV & $\begin{array}{l}\text { 'My suspicions include: bruises, dementia, forgetful, unkempt, dressed } \\
\text { inappropriately ....' }\end{array}$ \\
\hline Time constraints & 'This is not something that can be solved in a 10-minute office visit.' \\
\hline $\begin{array}{l}\text { Lack knowledge about appropriate } \\
\text { resources for older IPV victims }\end{array}$ & 'We are not aware of IPV resources' \\
\hline \multicolumn{2}{|l|}{ Community Agencies } \\
\hline Agencies serving seniors & $\begin{array}{l}\text { 'There is an absence of IPV information in the senior centers. They do not deal with } \\
\text { IPV.' }\end{array}$ \\
\hline IPV agencies & $\begin{array}{l}\text { 'The local shelter operates from a perspective that is usually not helpful to older } \\
\text { women. These women are not going to leave the relationship. The shelter thinks } \\
\text { they should. The agency needs to understand that the goal is to help women figure } \\
\text { out how to make something better in the relationship. The more empowered } \\
\text { women have already left the relationship.' }\end{array}$ \\
\hline $\begin{array}{l}\text { Other community agencies } \\
\text { (eg, police, APS) }\end{array}$ & $\begin{array}{l}\text { 'Got a page last night from a patient's son. The husband was beating up the wife. He } \\
\text { called the police, but when the police came, they said she wasn't beat up enough to } \\
\text { take him to jail. She had some scratches on her arms. They [APS] are not really an } \\
\text { agency to be used with IPV. They do well with people who are neglected and their } \\
\text { families are not supportive.' }\end{array}$ \\
\hline
\end{tabular}

\section{Do Ask; Refer It}

This category includes thorough identification and limited management ( 3 providers). Providers in this category may do a good job of identifying IPV but do not fully understand the needs of the older victim or that IPV management requires using a "chronic disease" model. For example, this physician was frustrated with the patient's noncompliance:

She comes in and complains to me. . I just wish she would listen to me.

Compliance issues are often a challenge with chronic illnesses. In addition, some providers may not know the nuances of managing an older victim with IPV, again seeking simple solutions. This physician reported dealing with an abusive retired couple in his practice: "I tell them that one of them needs to get a job."

\section{Barriers to Identifying and Managing Older Women Patients with IPV}

This second overarching theme corresponds in some respects with the theme just described. In an ideal world, all providers would be functioning at the "Do ask; do manage," levels of identification and management. However, the focus group participants mentioned specific barriers that either prevented or reduced a provider's ability to "make it" into that category. Participants described 3 distinct types of barriers: (1) barriers related to the victim, (2) barriers related to the providers' lack of knowledge or skills, and (3) barriers caused by a limited or lack of community response and services. These are discussed below. Providers' comments illustrating these barriers are presented in Table 3.

\section{Victim Barriers}

Most of the victim barriers discussed by the focus group participants related to patients' differing expectations that may exist as a result of generational or socioeconomic issues. With respect to generational issues, they mentioned that many of their older women patients do not want to complain too much and/or are less open about "airing their dirty laundry" or that they have lived with a "man-incharge" mentality. 


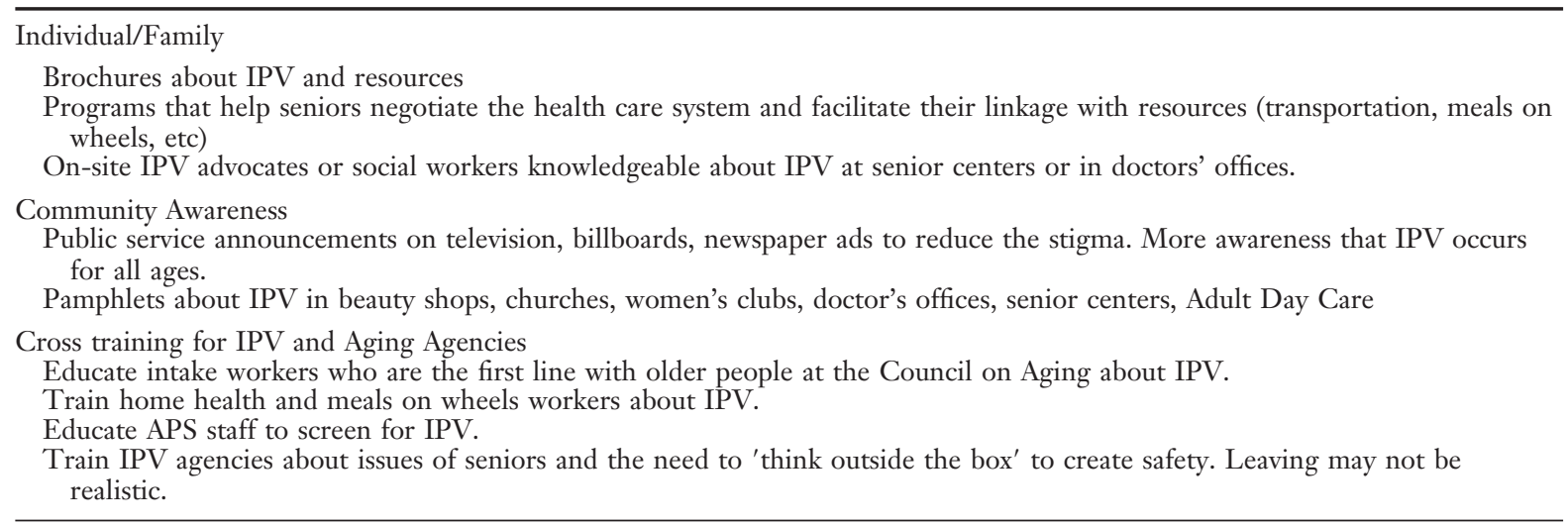

Because many of these women have been in long-term marriages, the couple's financial, social, and emotional lives are intertwined. Those with higher incomes may be less forthcoming about an IPV situation or reluctant to seek outside help because of embarrassment and pride. Addressing the IPV may result in a loss of privilege to which they have become accustomed. Those with lower incomes may have few, if any, resources (eg, money, insurance, support network) that would allow them to seek counseling or perhaps even to leave their situation. This can be frustrating for the provider. One physician noted: "You can refer them, but if they won't go you're stuck."

\section{Provider Barriers}

The identified provider barriers relate primarily, although not exclusively, to a lack of knowledge about the existence of IPV among older women. For example, although some providers were routinely asking younger women about IPV, they were not asking older women. In addition, providers seem to have a limited scope of the "red flag" medical and mental health symptoms associated with IPV (discussed above). Others said that because a patient is older than 60 , it must be elder abuse or neglect rather than IPV. The lack of knowledge regarding appropriate community referral sources for IPV was also a barrier. For example, physicians told us that if they suspected an IPV situation, they called Adult Protective Service (APS) because the patient was older than 60.*

* In Ohio, as in other states, the elder abuse statute identifies persons over age 60 who are handicapped by the infirmities of aging or who has a physical or mental impairment

\section{Community Agencies}

Barriers were found to exist for community agencies, those serving older women as well as those serving IPV victims. Participants mentioned that IPV agencies were not aware of the unique needs of older women or were unable to accommodate those needs in a shelter set up to serve younger women with children. In addition, persons working in agencies that dealt specifically with the aging population have not been trained to identify IPV victims. Finally, police and the legal system did not always respond appropriately, and some districts have not been set up to protect older victims.

\section{Strategies Suggested to Enhance Awareness and Services}

The third and final theme identified from the focus groups relates to strategies that enhance awareness and services for older women experiencing IPV. If implemented, these ideas may be useful strategies for breaking down some of the barriers described above, thereby facilitating the movement of providers toward the "Do ask; do manage" category. One provider said, "Focus $10 \%$ on physicians and $90 \%$ on community." Providers told us that increasing public awareness of IPV among all women would make their jobs easier.

I can ask, but they do not necessarily come forward. People need to realize it is abuse.

The primary targets for the strategies were: (1) the individual and family, (2) the community, (3) training agencies who serve seniors about IPV and IPV agencies about the issues of seniors (Table 4).

which prevents the person from providing for the persons own care or protection. (OH Revised Code 5101.61). 
Another major focus for increasing awareness was to train health care providers. Focus group participants that were categorized in the "Do ask; do manage" category based on their self-reported behaviors, outlined specific kinds of training that might help providers better identify and manage IPV patients. These included: (1) learn more about the difference between elder abuse and IPV and how these differences could be distinguished, (2) acquire a list of "red flag" symptoms or diagnoses that are associated with IPV, (3) learn about the best ways to elicit this sensitive information and how to discuss these situations with their older female patients, and (4) learn about and understand appropriate services for referring older patients with IPV.

\section{Discussion}

The purpose of this study was to understand primary care providers' (physicians, nurse practitioners, and physician assistants) awareness of IPV among women older than 55. It is likely that all the providers who participated in this study have older women with IPV in their practices. In fact, further probing with the questions, "do you have older female patients with chronic physical or somatic complaints or mental health issues," resulted in discussion about a "problem patient" in the practice who had a difficult marriage. However, only a few of the providers were screening older women for IPV. Their reasons for not screening were similar to those already documented in the literature. ${ }^{15-17}$

Although 4 providers were in the "Don't ask; don't know" category, most fell in the middle categories, where some awareness and management about IPV among their patients was evident, and there was an openness to considering IPV in older patients. These providers expressed a willingness to improve their IPV identification skills and to become more aware of available resources and the special needs of older women with IPV.

Researchers have demonstrated that increased IPV screening and changes in provider knowledge and attitudes about IPV occurs with chart prompts, ongoing educational efforts, and feedback about IPV management through continuous quality improvement techniques. ${ }^{25-29}$ In addition, having a system-wide approach for managing IPV victims with on-site or easily accessible IPV referrals, like the Kaiser system, improves IPV management by providers. ${ }^{30}$ One site that was part of a network of clinics, discussed the ease of managing their patients with alcohol problems because they had an on-site alcohol counselor.

Providers expressed the need to have a better understanding of the illnesses commonly associated with IPV. Educating and encouraging providers to focus IPV screening on those patients with the "red flag" symptoms and diagnoses associated with IPV, such as injuries, chronic pain, irritable bowel syndrome, depression, post-traumatic stress disorder, etc $^{6,7,31,32}$ will target IPV identification efforts to a higher risk group. This may increase the detection of IPV victims and perhaps limit providers' frustration with poor yields from their screening efforts. Helping providers adopt a "chronic disease" management mindset for IPV (what "do ask; do manage" providers were doing) may assist them in pacing themselves for the ongoing evaluation and management required with IPV in the health care setting, especially in older victims.

The other challenge with older victims is the lack of services available to meet their needs. APS, which was a common referral source for those providing limited management, has typically focused on elder abuse and neglect. Constrained by tight budgets and limited manpower, APS staff often focus on competency issues and may not be trained to identify IPV. Training intake workers to screen and refer IPV victims to the appropriate resources is needed and may ultimately result in better care for older abused clients [Collins T, personal communication, 2002 Oct].

On the other hand, IPV agencies, whose services usually focus on younger women, need to begin to accommodate older victims. Some authors have done an excellent job of outlining how IPV agencies and agencies that serve the elderly can collaborate. $^{22,33,34}$ Examples include information and programs at senior centers about IPV, emergency shelters at nursing homes for elderly IPV victims, and training outreach workers, such as Meals on Wheels and home health aides, to be aware the signs of IPV. In addition, because older victims may be unwilling to leave an abusive marriage, ${ }^{35}$ agencies need to be creative in providing assistance and safety within the home.

Providers acknowledged that their jobs would be easier if there were more awareness about IPV and understanding that abuse is not "normal" in a relationship. Therefore, ongoing efforts to fund com- 
munity-wide prevention campaigns are important by foundations and government agencies.

Several limitations to this study should be cited. Data are self-reported, which does not necessarily represent what is actually done. Qualitative research is not generalizable but is true to the locale studied. Attempts were made to examine the "validity" of the data in the qualitative sense by presenting the model to other physicians. Disclosure may have been hindered because the facilitator was a peer. Both focus groups and individual interviews were used for data collection; this may have altered the degree and richness of disclosure. When several physicians from a practice were present, they often discussed common older patients of concern and their insights were additive in nature. However, because of the nature of the provider lunch hour and time constraints, this was difficult to control. We attempted to increase the level of sharing in the interview format by probing with questions about a provider's experiences. We did not collect individual data on provider's level of training or prior experience with domestic violence. Despite these realities, these data give insight into a common problem in primary care, IPV, and a population that is often ignored in regard to this issue. With the expansion of the senior segment of the US population, the issue of older women and IPV will only increase. Communities, agencies, and health providers are encouraged to face this issue proactively.

Thanks to Bonnie Fisher and Elizabeth Gothelf for their enthusiasm and thoughtfulness as members of the research team.

\section{References}

1. Saltzman L, Fanslow J, McMahon P, Shelley G. Intimate partner violence surveillance uniform definitions and recommended data elements. Atlanta: Centers for Disease Control and Prevention; 1999.

2. Elliott B, Johnson M. Domestic violence in a primary care setting: Patterns and prevalence. Arch Fam Med 1995;4:113-9.

3. Gin N, Rucker L, Frayne S, Cygan R, Habbell F. Prevalence of intimate partner violence among patients in three ambulatory care internal medicine clinics. J Gen Intern Med 1991;6:317-22.

4. Hamberger L, Saunders D, Hovey M. Prevalence of domestic violence in community practice and rate of physician inquiry. Arch Fam Med 1992;24:283-7.

5. Deleted in proof.

6. Coker A, Smith P, Bethea L, King M, McKeown R.
Physical health consequences of physical and psychological intimate partner violence. Arch Fam Med 2000;9:451-7.

7. Campbell J. Health consequences of intimate partner violence. Lancet 2002;359:1331-6.

8. Domestic violence: Educational bulletin number 257. Washington DC: American College of Obstetrics and Gynecology; 1999.

9. American College of Physicians. Domestic violence: position paper of the American College of Physicians. Philadelphia: American College of Physicians; 1996.

10. American Medical Association Diagnostic and Treatment Guidelines on Domestic Violence. Arch Fam Med 1992;1:39-47.

11. Lapidus G, Cooke M, Gelven E, Sherman K, Duncan M, Banco L. A statewide survey of domestic violence screening behaviors among pediatricians and family physicians. Arch Pediatr Adolesc Med 2002;156:332-6.

12. Institute of Medicine. Confronting chronic neglect: The education and training of health professionals on family violence. Washington DC: National Academy Press; 2002.

13. Rodriguez M, Bauer H, McLoughlin E, Grumbach K. Screening and intervention for intimate partner abuse: practice and attitudes of primary care physicians. JAMA 1999;282:468-74.

14. Elliott L, Nerney M, Jones T, Friedmann P. Barriers to screening for domestic violence. J Gen Intern Med 2002;17:112-6.

15. Sugg N, Thompson R, Thompson D, Maiuro R, Rivara F. Domestic violence and primary care: attitudes, practices, and beliefs. Arch Fam Med 1999;8: 301-6.

16. Sugg N, Inui T. Primary care physicians response to domestic violence: opening Pandora's box. JAMA 1992;267:3157-60.

17. Waalen J, Goodwin M, Spitz A, Petersen R, Saltzman L. Screening for intimate partner violence by health care providers. Am J Prevent Med 2000;19: 230-7.

18. D'Avolio D, Hawkins J, Haggerty L, et al. Screening for abuse: barriers and opportunities. Health Care Women Int 2001;22:349-62.

19. Rovi S, Mouton C. Domestic violence education in family practice residencies. Fam Med 1999;31:398403.

20. American Association for Retired Persons. Abused elders or older battered women? Washington DC: American Association for Retired Persons; 1992.

21. Vinton L. Working with abused older women from a feminist perspective. J Women Aging 1999;11:85100 .

22. Brandl B, Raymond J. Unrecognized elder abuse victims. Older abused women. J Case Manag 1997; $6: 62-8$. 
23. Ethnograph. A program for the analysis of text based data [computer program]. Version 5.0. London: Scolari; 1998.

24. Borkan J. Immersion/crystallization. In: Miller W, editor. Doing qualitative research. 2nd ed. Thousand Oaks (CA): Sage Publications; 1999. p. 179-94.

25. Thompson RS, Meyer BA, Smith-DiJulio K, et al. A training program to improve domestic violence identification and management in primary care: preliminary results. Violence Vict 1998 13:395-410.

26. Scholle S, Buranosky R, Hanusa B, Ranieri L, Dowd $\mathrm{K}$, Valappil B. Routine screening for intimate partner violence in an obstetrics and gynecology clinic. Am J Public Health 2003;93:1070-2.

27. Davidson L, Grisso J, Garcia-Moreno C, Garcia J, King VJ, Marchant S. Training programs for healthcare professionals in domestic violence. J Womens Health Gend Based Med 2001;10:953-69.

28. Knight R, Remington P. Training internal medicine residents to screen for domestic violence. J Womens Health Gend Based Med 2000;9:167-74.

29. Campbell J, Coben J, McLoughlin E, et al. An evaluation of a system-change training model to improve emergency department response to battered women. Acad Emerg Med 2001;8:131-8.

30. McCaw B, Berman W, Syme S, Hunkeler E. Beyond screening for domestic violence: a systems model approach in a managed care setting. Am J Prev Med 2001;21:170-6.

31. Drossman D, Lesserman J, Rachman G, Zhiming L, Gluck H, Toomey T. Sexual and physical abuse in women with functional or organic gastrointestinal disorders. Ann Intern Med 1990;113:828.

32. Golding J. Intimate partner violence as a risk factor for mental disorders: a meta-analysis. J Fam Violence 1999;14:99-132.

33. Vinton L, Altholz JA, Thea L-B. A five year follow up study of domestic violence programming for older battered women. J Women Aging 1997;9:3-15.

34. Vinton L. A nationwide survey of domestic violence shelter's programming for older women. Violence Against Women 1998;4:559-71.

35. Zink T, Regan S, Jacobson J, Pabst S. Cohort, period, and aging effects: a qualitative study of older women's reasons for remaining in abusive relationships. Violence Against Women 2003;9:1429-41. 